\title{
Erratum to: From carrot to clinic: an overview of the retinoic acid signaling pathway
}

\author{
Maria Theodosiou • Vincent Laudet • \\ Michael Schubert
}

Published online: 14 April 2010

(C) Springer Basel AG 2010

\section{Erratum to: Cell Mol Life Sci \\ DOI 10.1007/s00018-010-0268-z}

During the editing process, a few chemical structures in Fig. 1 were reproduced incorrectly: a double bond was shifted in the structure of $\beta$-carotene (Fig. 1a), two methyl groups were cut from the hexane ring of 5,8-epoxy-alltrans retinoic acid (Fig. 1a) and, lastly, a carboxylic acid group $(\mathrm{COOH})$ was missing from the BMS614 structure (Fig. 1b). The corrected structures have now been incorporated into Fig. 1.

The online version of the original article can be found under doi:10.1007/s00018-010-0268-z.

M. Theodosiou · V. Laudet · M. Schubert $(\bowtie)$

Institut de Génomique Fonctionnelle de Lyon,

Université de Lyon (Université Lyon 1, CNRS, INRA,

Ecole Normale Supérieure de Lyon), 46 allée d'Italie,

69364 Lyon Cedex 07, France

e-mail: Michael.Schubert@ens-lyon.fr

M. Theodosiou

e-mail: Maria.Theodosiou@ens-lyon.fr

V. Laudet

e-mail: Vincent.Laudet@ens-lyon.fr 
A
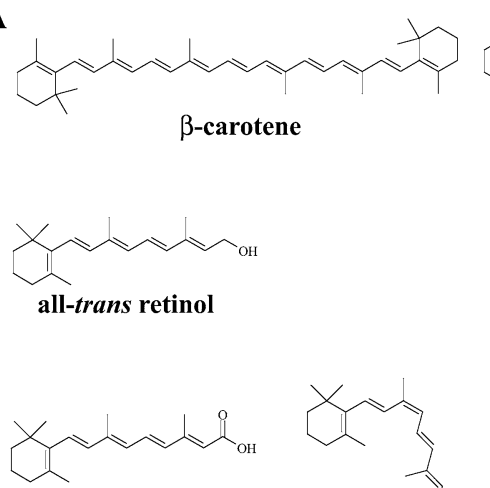

all-trans retinoic acid

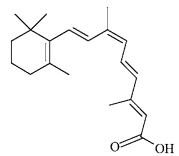

9-cis retinoic acid

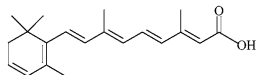

3,4-didehydro-all-trans retinoic acid

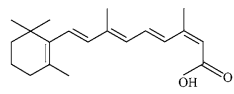

13-cis retinoic acid

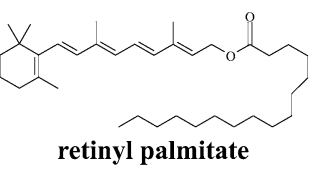

retinyl palmitate

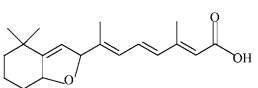

5,8-epoxy-all-trans retinoic acid
B

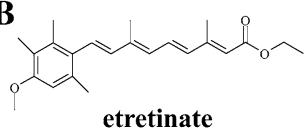<smiles>Cc1cc(/C=C/c2ccc(C(C)(C)C)cc2)ccc1/C=C/c1ccccc1</smiles>

TTNPB

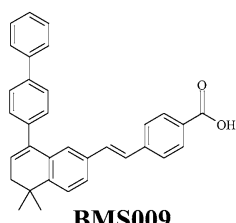

BMS009<smiles>CC(=O)c1ccc(C(C)c2cc(C)c3c(C)c2CCC3(C)C)cc1</smiles>

LG100268
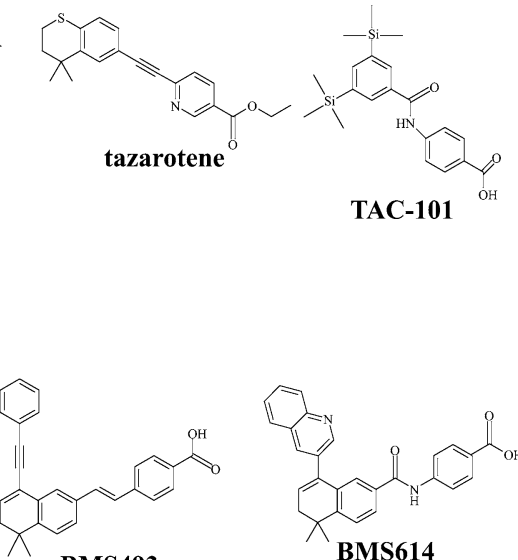

BMS493

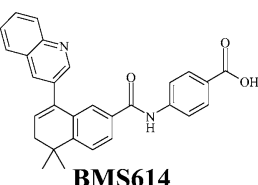

BMS614

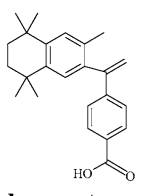

bexarotene 